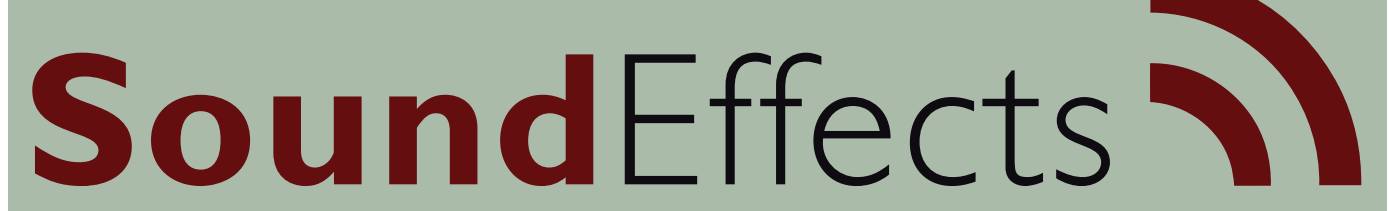

An Interdisciplinary Journal of Sound and Sound Experience

Marie Koldkjær Højlund

\title{
Beyond insulation and isolation \\ - Towards an attuning approach to noise in hospitals
}

\section{Marie Kold kjæer Højlund}

Ph.D. Fellow, Audio Design

School of Communication and Culture

Aarhus University 


\begin{abstract}
Most research on the acoustic environment in the modern Western hospital identifies raised noise levels as the main causal explanation for ranking noise as a critical stressor for patients, relatives and staff. Therefore, the most widely used strategies to tackle the problem in practice are insulation and isolation strategies to reduce measurable and perceptual noise levels. However, these strategies do not actively support the need to feel like an integral part of the shared hospital environment, which is a key element in creating healing environments, according to the paradigm of Evidence-Based Design and Healing Architecture. This article suggests that the gap in contemporary research is intimately linked to a reductionist framework underlying the field, which is incapable of accommodating the multisensory and atmospheric conditions amplifying the experience of noise. This article argues that an attuning approach should be included in the field to help bridge the gap by offering active ways of attuning to the shared environment.
\end{abstract}

'In short, in normal everyday life, when I perceive, I am always perceiving from somewhere, exposed to my surroundings and in the process of doing something. Far from being simply epiphenomena, these contextual dimensions are an integral part of perceptual activity'. (Thibaud, 2011, p. 205)

\title{
Introduction
}

During the 2010s the Danish regions are building new hospitals to improve healthcare by putting patients first as part of a larger paradigm shift in healthcare over the last 30 years - from focussing purely on curing disease to including concerns about how to support the healing process. To improve healthcare settings these visions are to be unfolded through the creation of healing environments, guided by research done in the field of Evidence-Based Design (EBD). A healing environment should be designed by reducing stressors and shielding the patient from a hectic environment, on the one hand, and by creating stimulating surroundings that can support the equally vital need to feel like an active and integral part of the environment, on the other.

In this context the acoustic environment has become a central concern, as research has shown that noise levels in the modern Western hospital exceed recommendations, and at the same time noise is consistently mentioned as a critical stressor for patients, staff and relatives (Busch-Vishniac et al., 2005). The research constituting the knowledge base for EBD recommendations on the noise problem has been dominated by two main approaches. The first of these is a noise reduction approach ${ }^{1}$ rooted in natural science and acoustics, which aims to achieve a 
measurable reduction of the overall sound level by the implementation of various insulation strategies in order to eliminate noise as effectively as possible, mainly by installing soundproofing material.

Based on data that questions the adequacy of the noise reduction approach, a second approach has emerged in the last decade advocating for a human-centred approach, rooted in interdisciplinary collaboration between natural, human and social sciences, focussing on the subjective experience of noise. According to this approach, focussing purely on reducing sound levels simplifies the complexity of the noise problem, and must be supplemented by an ongoing and multifaceted effort to chart a course for quiet or calm for patients. Therefore, this approach recommends isolation strategies to reduce the experience of annoying sounds (e.g. by reducing reverberation times), and by adding positive sounds (e.g. by the use of healing music in headphones) offering the individual patient a momentary island of rest from the hectic environment. The combination of the noise reduction approach and the human-centred approach fits well within the EBD recommendations to both reduce stressors and provide positive stimulation, thereby holding out a promise of support in creating a healing environment. However, an analysis of the strategies of these two approaches reveals a gap in terms of adequately meeting the need to feel like an active and integral part of the environment in situations where it is not favourable to be insulated or isolated from the shared environment.

This article argues that the shared reductionist framework underlying the existing approaches implies a radical split between subjects and objects and a passive perception model rooted in sensory atomism that prevents taking the appropriate steps to close the gap, as it is unsuitable to accommodate the complex multisensory and atmospheric conditions that are central parts of the noise problem in shared hospital spaces. The main contribution of this article is therefore to argue for the importance of including a third attuning approach in the field, based on a foundational framework capable of addressing the gap. The article consequently outlines an attuning approach based on a non-representational framework in which attunement refers to a capacity to actively sense, amplify and attend to difference shaped by the atmosphere, all of which contribute to and condition what and how something appears in the world (Ash \& Gallacher, 2015, p. 70). This framework allows research that addresses the gap, but does not fit within the reductionist framework, to be unfolded. Research that identifies non-acoustical and contextual factors as central parts of the noise problem in hospitals. Furthermore, it illuminates valid reasons for the gap identified in the field of EBD, because the noise reduction approach and the human-centred approach focus on diagnosing what constitutes noise or quietness, thereby failing to consider how the patients' appraisal of sounds also depends on the possibilities of acting in and responding to the environment. Including the attuning approach in the field can therefore help specify the main concerns when 
designing attuning strategies to facilitate ways to feel like an integral part of the environment, ways which are currently missing in the field.

The article ends by discussing the advantages of adopting Reflexive Epistemological Diversity (David, 2005, p. 22) in EBD, which would allow the inclusion of alternative research that builds on different foundational frameworks. This expansion would help strengthen the explanatory validity in the field, which is needed to create healing environments in the complex Danish hospital environments in the future.

\section{Addressing noise in hospitals}

From 2010 to 2020 a number of super hospitals are being built in Denmark with the explicit aim of improving healthcare through patient-centred care. To unfold the visions, key themes guide the process, including how the environment impacts on patients and staff, and how design and architecture can contribute to the healing process. ${ }^{2}$ There is a growing demand for basing such decisions on scientifically based knowledge, which has partly been met in publications such as Hospitals of the Senses (Sansernes Hospital [Dirckinck-Holmfeld et al., 2007]) and Healing Architecture (Helende Arkitektur [Frandsen et al., 2009]). This literature gives design recommendations on how to create healing environments, based on research done in the area of EBD, which has become an international trend in healthcare design. To meet the evidence-based criteria of research validity, EBD recommendations are derived from literature reviews of credible research in the field of hospital noise, which are regarded as the primary source of knowledge when approaching the problem in connection with the construction of the new hospitals (Frandsen et al., 2009, p. 79).

'Unnecessary noise, then, is the most cruel absence of care which can be inflicted either on sick or well' (Nightingale, 1946, p. 27). This quote recurs frequently in both public and academic presentations on the growing noise problem in the modern Western hospital. The quote is taken from the book Notes on Nursing: What It Is, and What It Is Not from 1859 by Florence Nightingale, the founder of modern nursing. Throughout the article different interpretations of the quote will serve as an illustrative framework for mapping the main approaches in the field, as well as other research that is not yet included in the field.

The quote is mostly used as above, without an intratextual context. The word then is ignored, after which the word unnecessary is taken to support the argument that the reduction of noise levels is the paramount concern in fighting the noise problem in hospitals (Busch-Vishniac et al., 2005, p. 3629; Call, 2007, p. 2). ${ }^{3}$ This interpretation reflects an acoustic noise concept in which loud sound has negative physical and psychological effects, and therefore the goal is to lower noise levels. To achieve this goal the noise reduction approach therefore recommends a range of insula- 
tion strategies such as installing insulation material and sound-absorbing panelling, eliminating excess overhead paging and culling extraneous alarms (Joseph \& Ulrich, 2007).

An alternative interpretation of the quote, taking the context of the chapter where the quote appears into consideration, will serve as an illustration of a second approach, which has come to dominate the field throughout the last decade. The quote appears in the middle of the fourth chapter 'Noise', which begins: 'Unnecessary noise, or noise that creates an expectation in the mind, is that which hurts a patient. It is rarely the loudness of the noise, the effect upon the organ of the ear itself, which appears to affect the sick' (Nightingale, 1946, p. 25). In this first sentence of the chapter unnecessary is defined as having nothing in particular to do with the loudness of the noises, an interpretation that is underlined in the following sentence: 'Unnecessary (although slight) noise injures a sick person much more than necessary noise (of a much greater amount)' (Nightingale, 1946, p. 27). Following this interpretation of Nightingale, the noise reduction approach has become increasingly contested as inadequate by a human-centred approach. This approach has argued for a shift towards a subjective noise concept defined as unwanted sound, not chasing silence, but facilitating perception of quiet and calm by stressing the importance of understanding the individual experience of annoyance (Johansson et al., 2012; Topf, 2000). This shift is supported by data collected in hospitals tackling the noise problem solely through insulation strategies, concluding that noise reduction as a cure and silence as a goal are not adequate (Wolf \& Madaras, 2012). The human-centred approach seeks to address perceived noise annoyance through detailed acoustic measurements combined with qualitative studies (Okcu et al., 2011, p. 1349) based on interdisciplinary collaborations (Ryherd et al., 2008, p. 23). The strategies proposed by this approach include creating positive environmental adjustments by reducing reverberation time, isolating the patients in single bedrooms, providing positive distractions through music intervention and adding continuous background sound called masking noise (DirckinckHolmfeld et al., 2007; Frandsen et al., 2009). Other strategies address cultural and behavioural patterns through alignment of people with continuous noise awareness and effort, for example through carving out blocks of daily 'quiet time' (Wolf \& Madaras, 2012). Taken together, the strategies strive to recognise the subjective and thus divergent experience and therefore target individual patients through isolation strategies that help them find islands of rest shielded from the hectic hospital environment.

Due to the emergence of the human-centred approach, the noise problem is increasingly approached as a complicated and ongoing problem with no easy solution, highlighting the importance of not only considering negative aspects, but also including qualitative features (Mackrill et al., 2013, p. 1). This direction reflects a 
general paradigm shift in research on complex and public sonic environments from no sound to quality sound, an approach that has been emerging in several disciplines. This work, termed 'soundscape research' (Kang et al., 2013), has disputed the idea that sound, unless organised in accepted musical structures, is always unnecessary and undesired by proving that the quality of life is not improved by removing sound, but rather by shaping its aspects, as 'fighting against noise pollution may not be the same as fighting for silence' (Thibaud \& Amphoux, 2013, p. 64). In other words, the univalent focus on noise understood purely as a nuisance is problematic when addressing complex sonic environments, and therefore issues of noise must be supplanted by reflections on aural comfort.

According to EBD, a healing environment is characterised by the fact that it meets the need to feel both protected from the hectic healthcare environment and to feel like an integral part of this environment, by empowering the patient to be able to actively choose privacy or engage in the environment at different times (Frandsen et al., 2009). These two vital needs are supported by research in the field of noise in hospitals (Mackrill et al., 2013, p. 5; Shattell et al., 2005, p. 168). Designing to achieve a healing environment therefore simultaneously reduces stressors and positively stimulates the senses through the interplay of art and architecture. A combination of the two main approaches seems to match these ideas, and may therefore prove capable of adequately addressing the noise problem. However, considering the individual shielding character of these strategies reveals that they are unsuitable in situations where insulation and isolation are not the most effective or feasible ways to meet the need to feel like an integral part of the environment. Therefore, the second part of this article will analyse the shared foundational framework underlying the existing approaches in order to expose possible reasons for these shortcomings.

\section{Reductionist framework}

The two approaches are based on the understanding that noise and not-noise are consistent concepts that can be fixed in various representational and dichotomous frameworks as noise versus not-noise or unwanted versus wanted sound. Both approaches suggest that there is something that can be separated and conceptualised in itself and thereby removed and/or described independently: The noise reduction approach because its quantitative premise is that noise can be objectified, measured and thus removed, and the human-centred approach because its qualitative premise is that it can comprehend and deal with noise in all its complexity by establishing a comprehensive general taxonomy to distinguish between the unwanted and wanted. 
Following the object-oriented philosophy of Graham Harman, this article argues that both approaches share an underlying reductionist framework based on 'undermining' and 'overmining' tactics (Harman, 2013, p. 43). Both approaches seek to handle complexity by capturing the essence of things (noise) either through 'undermining' by reducing things downwards to their smallest components, as when the noise reduction approach assumes a correspondence between observation and real world, or through 'overmining' by reducing things upwards into broad dichotomous concepts, as seen in the human-centred approach, which regards noise as nothing more than the effect on the individual subject. When both approaches are included in EBD, the result is 'duomining', where the field not only depends on defining measurable criteria for noise, but is also commensurable with human understandings of general categories such as noise. 'Duomining' ignores the fact that both the instruments for measuring and the categories to describe noise constitute the object under study, by both reducing and amplifying certain aspects of it. In this way, 'duomining' demands exaggeration as a primary tool, as expressed in the Cartesian reductionist framework, which presupposes a dichotomous divide between the experiencing subject and the object (noise).

According to Martin Heidegger, taking such a subject/object dichotomy as a point of departure will lead us to fundamentally mischaracterise the prevalent engagement in the everyday world in which we are usually unreflectively immersed. $\mathrm{He}$ diagnoses this as being the result of a prevalent modern worldview, attempting to establish mastery and control over an unruly world (Thomson, 2011). As a consequence of this radical split the human is considered a passive receptor of raw sensory data, who fills in the gaps through accumulation of knowledge in a chaotic environment where structure is imposed on the world by building an internal model (Clarke, 2005, p. 22; Ingold, 2011, p. 282). Furthermore, it presumes a division of the senses as different channels that can be individually addressed as discrete faculties, and thus encourages research to start in 'sensory atomism' (Ihde, 2007, p. 43). This can be observed when sound and noise and hearing are understood as a passive sense, cut off from the other senses and their bodily interplay. In this view, the overload of sound (raw sensory data) bombarding the passive receiver makes noise an unhealthy, contaminating stressor that causes disease (Biddle, 2009). Therefore, the noisy acoustic environment in hospitals creates a tension amplified by the cultural understanding that quietness is the most appropriate environment for healing (Rice, 2013, p. 29).

Dividing the subject from objects and other subjects forms the groundwork for what Heidegger terms 'subjectivism'. This is a perspective in which an objective realm is separated from isolated subjects and so needs to be mastered by the normative and practical activities of these subjects, as reflected in the existing strategies. The attempt to skip the integral and practical entwinement of self and world 
will lead to 'enframing', when the failed attempt to control the world turns on itself, with the result that the subject is increasingly transformed into just another object to be controlled. This tendency can be traced in the attempt of isolation strategies to control subject behaviour through, for example, 'quiet time' and urging individuals to seek harmony elsewhere, for instance by withdrawing into headspace through the use of healing music, which is believed to 'work' as a kind of medicine controlling the patient's mind (Lind, 2007, p. 211). 'Aesthetics becomes a psychology that proceeds in the manner of the natural sciences; that is, states of feeling become self-evident facts to be subjected to experiments, observation, and measurement' (Heidegger in Thomson, 2011, p. 59). Together the insulation and isolation strategies represent efforts to resist and prevent what Erving Goffman identified as 'contaminative exposure' (Rice, 2013, p. 44). This worldview assumes that there is a quiet and balanced world somewhere, and that our job therefore is to restore the balance by removing noise through protective regulatory measures until the problem has been solved. Research on noise has therefore been focussed on explaining how people get stressed and fall ill owing to noise pollution, and the strategies aim at removing noise as much as possible to create a healthy and healing environment.

However, the emerging human-centred approach has increasingly revealed that the current gap in the field is related to the limitations of such a reductionist framework. For instance, Dirckinck-Holmfeld et al. state that the sensory atomism in the field represents a serious limitation, as research consequently has to guess what role the multisensory and atmospheric intertwinement plays. They call for future research to give name to the ineffable, which would demand another framework able to accommodate 'what we cannot know' (Dirckinck-Holmfeld et al., 2007, p. 196, my translation) in the EBD domain. Based on the analysis presented in this part of the article, these issues will thus remain ineffable if the field continues to be based solely on a reductionist framework that is incapable of reflecting the complexity of the problem being approached (Annerstedt, 2012). Consequently, the next part of the article will outline a third attuning approach, based on a framework which is capable of accommodating the multisensory and contextual aspects with a view to revealing the potential of this approach for outlining a way to bridge the gap in contemporary research.

\section{Towards an attuning approach}

Research outside the field of EBD focussing on listening in hospitals has investigated the obstructive as well as encouraging factors when it comes to feeling like a part of the hospital environment. These studies have been conducted using different qualitative methods, including ethnographical and phenomenological methods, and stress the need to address the noise problem with a focus on how the 
situational multisensory, corporeal and affective context mediates and facilitates listening as a primary sensory mode. Therefore, they point to the need for comprehensive assessment with a view to placing noise in relation to other non-acoustical aspects (Mackrill et al., 2013, p. 6). According to anthropologist Tom Rice, who spent a year in an English hospital focussing on the listening experience of the patients, the hospital environment has an 'unusual atmosphere of sensory absences' (Rice, 2003, p. 5), encouraging the development of an intense sonic sensitivity. This is due to a general impoverishment of non-auditory stimuli, leading to a sense of stasis, which is amplified by corporal confinement in bed (Johansson et al., 2012, p. 113; Radley \& Taylor, 2003). The experience of noise is therefore intimately connected to and cannot be demarcated from contextual conditions, jointly creating a feeling of being disconnected, isolated, exposed and disorientated (Shattell et al., 2005 , p. 168). Rather than producing affectively numbed or desensitised bodies, this atmosphere gives rise to a heightened sensibility in the auditive area by actively sensitising listening. The complex and ambiguous relationship between the acoustic environment and listening therefore takes on a central, disturbing and reassuring role in navigating and negotiating the role of being in hospitals to both orient and connect, but also shield and restore (Johansson et al., 2012, p. 112; Shattell et al., 2005, p. 161).

However, the acoustic environment in hospitals is distinctly different from other domestic and public spaces, because the sounds of other sick people, medical practices and equipment define the overall hospital atmosphere as a medical space. Moreover, it is dominated by many affective intrusive and sudden sounds, amplified by the fact that they often cannot be confirmed and prepared for in visual or other sensory modalities or balanced with other non-medical sounds. Therefore, the soundscape contributes to a feeling of being in the middle of something uncontrollable. Furthermore, the many alarms that make the body acoustically present create what Rice describes as a feeling of 'sonic incontinence' (Rice, 2013, p. 180), amplified by the experience of a subdued environment and a lack of dynamic non-medical background sounds (Johansson et al., 2012, p. 113), forming a system of control which the institution enforces. Understanding the ongoing annoyance and appraisal of different sounds in this perspective, noise might as well consist of small, quiet and muted sounds that reinforce the feeling of being present in a system of control without being in control.

The combination of the intense sonic sensibility and the uncontrollable soundscape calls upon specific attentive listening modes such as 'monitory listening' (is something wrong?) and 'diagnostic listening' (what is wrong?) (Rice, 2013, p. 181). Following Andringa and Lanser (2013), directed attentional modes demand a lot of energy to distinguish between important and unimportant sounds, which can lead to directed attentional fatigue and exhaustion, if they are not complemented by 
other less demanding modes of perception. Less focussed and vague modes of hearing or overhearing are not directed towards diagnosing specific sounds, and therefore do not make great demands on directed attention. Such restorative modes therefore provide time to restore the capacity for direct attention and reduce arousal (Andringa \& Lanser, 2013, p. 1445). Facilitating these modes of hearing can therefore take on a key role for establishing audible safety and thus enhancing the feeling of being in control of the situation.

As the hospital environment with its general lack of dynamic background sounds often does not facilitate these modes of listening, patients spend energy trying to counterbalance demanding listening modes by turning a deaf ear to feel shielded and thus restore listening attention. The patients' ability to successfully cope therefore depends on their ability to successfully habituate the sounds in order to overhear them, which is made difficult by their affective character and the patients' inability to control them. In other words, as patients are left without possibilities or skills to actively habituate and overhear, the role of the acoustic environment as reassuring and restorative is obstructed and transformed into an urgent need for zones of privacy (Wiese, 2010, p. 100). This strand of research thus points towards the need to facilitate less attentive hearing modes as a fruitful way to restore attention and cope effectively, providing both the needed indicators of safety in the unsafe and demanding sonic environment and active possibilities to actively attune to the patterns and rhythms of hospital life.

Taking these insights into consideration calls for a third interpretation of Nightingale that is outlined in the rest of the chapter on noise and the overall message of the book, with a view to addressing the complexity of the noise problem adequately. Throughout the first pages of the chapter on noise Nightingale unfolds the argument that sound only becomes noise and thus unnecessary when it appears to be unresolved and meaningless, but demands an unfair amount of attention. She uses the startling effect of sudden sounds in relation to a quiet background and the unresolved effect of overhearing fragmental conversations and acousmatic sounds ${ }^{4}$ while confined in bed as illustrative examples. This state of affairs gives rise to a frightening feeling of confusion which counteracts the healing process. The word then in the famous quote mentioned above thus takes on an important role as a reference to these pages on the meaning of the word unnecessary. The chapter on noise is consistent with the main argument of the book that the overall environment for healing has a huge impact on the sick (Nightingale, 1946, p. 5). The noise problem should therefore be considered in interplay with the general lack of positive multisensory stimulations and possibilities to actively cope, which together facilitate attentive listening modes foregrounding noise as a main stressor. This third interpretation fits Hillel Schwartz's conclusion that 'Nightingale's sense of noise- 
lessness was ecological, aristocratic, and metaphysical: a permeating "atmosphere"' (Schwartz, 2013, p. 274).

On this basis the article argues that there is an urgent need for EBD to be able to adequately respond to the third interpretation of Nightingale, emphasising how negatively the inability to actively exert control over a stressor influences soundrelated annoyance (Topf, 2000, p. 521). This perspective suggests that the experience of wanted or unwanted sound also depends on the possibilities of acting and responding to the environment, calling for strategies that offer a diversity of acoustic situations to be actively chosen and co-created as active coping strategies to feel like an integral part of the shared hospital environment. Therefore, the article suggests an attuning approach to operationalise this perspective in the field through a non-representational framework that develops a vocabulary for understanding the multiple and shifting relations between humans and their environment. Whereas representational theories study the mind and its operations as preconditions for action, non-representational theory is an umbrella term for diverse work that seeks to cope better with our complex multisensory worlds by taking as its starting point unreflexive, preobjective and habitual interactions and analysing affective resonances of that which is unsaid or barely sayable (Vannini, 2015, p. 8). Ash and Gallacher propose attunement as a way to engage in this non-representational background, as it constitutes a basic capacity to sense, amplify and attend to difference shaped by the atmosphere, which together act as 'the conditions of possibility for what and how something appears in the world, before it is organized through internal self-narration, the representational logics of language or a theoretical account of the senses as a series of discrete faculties' (Ash \& Gallacher, 2015, p. 70). An attuning approach seeks to acknowledge how backgrounds that often fall out of common awareness and habitual dispositions both shape our capacity for action and constitute a basis on which particular things show up and take on significance, for example noise. The previously ineffable opens up as a space of possibilities for intervention and innovation as well as domination and control.

On this account the intense sonic sensibility in hospitals promoting attentive listening modes is a consequence of an environment that obstructs attuning by promoting a significant subject/object division through confinement in bed, lack of control and an atmosphere of absence. Heidegger suggests that such atmospheres of Ungestimmtheit are the most powerful, as they are easily overlooked because they appear empty, though at the same time create a feeling of being alienated, standing outside or against the environment (Flatley, 2008, p. 22). Therefore, the existing insulation and isolation strategies unintentionally reinforce this feeling of standing outside the environment, unable to act, as they gesture towards silence. According to Don Ihde, 'Gesturing toward silence enhances listening' (Ihde, 2007, p. 222), as the focus on trying to exclude other sounds negates itself and produces the con- 
trary effect of increased vulnerability. The more we gesture towards silence, the more radical the intrusions of formerly unobtrusive disturbances become. Eric Clarke compares this type of listening to certain forms of musical listening, where we listen as if the music was autonomous and outside the environment. This listening mode is different from everyday listening, because it encourages the listener to turn away from the wider environment in searching for meaning, as it affords internalised contemplation (Clarke, 2005, p. 138). The hospital environment affords this kind of detached and attentive listening, limiting the perceivers' capacity to intervene in or act upon the immediate environment through less attentive listening modes that would allow active coping strategies.

Therefore, the foundation for feeling like an integral part of the hospital environment must be established before such detached and attentive listening modes become dominant, and this is done by acknowledging that the attuning relationships between the self and the world involve a two-way process and are mutually constituting. Jean-Paul Thibaud suggests that we do not perceive atmospheres as such; instead we perceive on the basis of atmospheres (Thibaud, 2011, p. 212). Hence, atmospheres are intermediary phenomena occurring between people and space as a sensory background that specifies the conditions under which phenomena emerge and appear. Following this line of thinking, the attuning approach addresses the atmospheric and multisensory conditions on the basis of which our perception depends, consisting of a reciprocal and shifting relationship that conditions us, but is also conditioned by us. This will offer a way to operationalise the concept of atmospheres in praxis and point to the importance of strategies to consider the fragile and changing temporal and spatial relations. Leaving static concepts such as noise/quiet behind reveals how rhythmic attunement to a familiar place may be confounded when the body is out of place, as in hospitals. But it also reveals how the environment can facilitate spatiotemporal patterns or 'reconfigure presence' to help us to integrate anew 'in a changed or unfamiliar space in order to regain ontological security' (Edensor, 2010, p. 5). As atmospheres are always in the process of emerging and transforming, attuning to the temporal aspect and habituation through repetitive actions inevitably has a neutralising effect on the affective impact (Højlund \& Kinch, 2014). So offering concrete ways to actively structure space and time could be a way to rethink the relationship between us and the environment through 'sensibilising practices' (Thibaud, 2014, p. 4), or what this article terms attuning strategies. Perception is thus connected to action, as it is through perceptual learning that we can designate a new way - active adaptive attunement - for listeners to optimise their resonance with environment. Adopting this viewpoint, the sense of control should be established in the attuning relationship between the person and the environment and not in the person (isolation strategies) or in the environment (insulation strategies). 
According to the ecological understanding of listening, as further developed by Clarke, this is how we normally navigate through sounds in the context of other sounds and situations, where ecological or overhearing listening modes lead to action and action modifies perception by exploring the source of the sound and, consequently, changing the way we perceive them (Clarke, 2005, p. 137). As different listening modes provide both distal and proximal situational awareness, the background attuned by overhearing can create a continual sense of place without requiring conscious attention and can still provide a safe feeling through offering 'ample opportunities for restoration' (Andringa et al., 2013, p. 15). In normal everyday environments we thus actively design our environment to afford inattentive listening modes to create reassuring atmospheres with, for instance, furniture, radios and hi-fi equipment, in order to thus mask unwanted sound and create a sonic climate that is perceived as pleasant (Hellström, 2003, p. 78). The ubiquitous use of music technologies today is regarded as a particularly effective device to which we turn in order to regulate ourselves as agents structuring materials of subjectivity (DeNora, 1999, p. 45). According to Annahid Kassabian, such musical practices facilitate inattentive listening or 'ubiquitous listening', which plays a key role in conditioning 'distributed subjectivity' - a condition that is non-individual and that renders identity as an emergent node in a constantly shifting field of sound, atmosphere and affect open to a network of listeners - to feel like part of a shared environment (Kassabian, 2013, p. 10). However, in the hospitals we are often not able to engage in 'ubiquitous listening' as a way to gain a sense of control and connection to the environment.

\section{Discussion}

EBD recommends that a healing environment in the hospital should meet the need both to feel protected from the hectic hospital environment and to feel like an integral part of it. However, the two dominant approaches in the auditory area (the noise reduction approach and the human-centred approach) share a reductionist framework which is incapable of addressing the complex multisensory and atmospheric conditions which play important roles in obstructing or facilitating the feeling of being an active and integral part of the environment. To bridge this gap the article has argued for the inclusion of a third attuning approach based on a nonrepresentational framework, allowing research that addresses the gap, but does not fit within the reductionist framework to be unfolded. This research reveals how the combination of the general atmosphere of absence, confinement in bed and lack of control creates an intense form of sonic sensibility in which the dynamic relationship between the patient and the acoustic environment plays a key role in creating or obstructing a healing environment. However, the nature of the acoustic environment creates an affective state of passive vulnerability that calls for attentive 
listening modes dominating the organisation of the experience of being a patient, while less attentive hearing modes that could allow for active attuning strategies for successful coping are obstructed. Including these insights in the field highlights that non-acoustic and contextual factors are central parts of the noise problem in hospitals. Introducing the attuning approach into the field can therefore help specify the main concerns when designing attuning strategies to facilitate ways of feeling like an integral part of the environment, which are currently missing in the field. Attuning strategies should thus be concerned with promoting a sense of control by facilitating and offering a diverse range of possibilities to engage in inattentive listening modes, thereby enabling patients and other groups to feel empowered to actively attune different situations and environments in hospitals. Recently in Denmark a few examples of initiatives aimed at offering the hospital patient some control over the acoustic environment can be found in the fields of music therapy and music medicine. First, patients at Aalborg Psychiatric Hospital are offered the choice between five different music genre-specific programmes in the form of a sound pillow (Bonde, 2011, p. 130). Second, an integrative sensory delivery room for Nordsjællands Hospital with dynamic light and audiovisual stimulation is currently being tested and evaluated, including interactive breathing exercises with waves to help women entrain their breathing to stimulate rhythms during labour. Third, at Herning Hospital a similar delivery room project is under evaluation, though the focus here is on offering patients the possibility of creating different zones and giving the users control of the character of the atmosphere. ${ }^{5}$

However, the accordance between the reductionist framework in the field and the EBD criteria for validity presents an obstacle for the inclusion of an attuning approach in the field.

The framework characterising the existing field of noise in hospitals is consistent with the cognitive traditions and laboratory methods prevalent in EBD, based on the evidence-based criteria for research validity. However, Stankos and Schwarz (2007) argue that if EBD is to remain relevant as a paradigm for the future, it must be able to address the messy complexity in the everyday context. This critique has compelled a general shift in the EBD literature from evidence-based to researchbased (Frandsen et al., 2009, p. 3) through the inclusion of alternative qualitative methods, as seen in the human-centred approach. However, the process of including such new criteria of validity poses problems for EBD, as the increasingly diverse interdisciplinary theory and methodology puts pressure on the comparability of EBD to evidence-based medicine, which has been an important part of its legitimisation in the healthcare industry. Therefore, previously the consequence has mainly been that research based on alternative methods and criteria of validity other than the ones accepted in EBD is either not included in the field or translated into the existing framework, supporting its presuppositions. This is not a viable 
solution, as research should be guided by a foundational framework that reflects the complexity of the problem being approached (Becker et al., 2011, p. 128), whereas the process of translation includes a risk of reducing and thus missing the potential of relevant research for helping to bridge the gap in the field. However, as health research often considers methods to be tools with no direct relation to the ontological and epistemological foundations, this problem is not easily spotted. The obvious answer would therefore be that EBD should rethink the theoretical and philosophical frameworks used to structure the research process, if these alternative methods are to be relevant alternatives to the existing methods. However, as Becker et al. and others argue, the EBD paradigm has a hard time rethinking baseline assumptions (Becker et al., 2011, p. 128). Therefore, the suggestion put forth in this article is that instead of opting for an either/or solution, a fruitful alternative is to consider how the field can embrace both/and, allowing more than one foundational framework to coexist within EBD through Reflexive Epistemological Diversity (RED).

Within the sociology of science and technology, Matthew David has proposed that the entrenchment within forms of reductionist and relativist epistemology can and should be overcome by adopting RED (David, 2005, p. 22). RED recognises the value of many forms of explanations, promoting interaction between different explanations, at different levels of causation and across the divide between different sciences. The prevalent view that insights from other epistemological traditions will result in confirming the falseness of any one tradition is to be replaced by a willingness to accept and open up to different causal explanations, as the complexity of the world is best approached in different ways on a number of levels. However, epistemological diversity does not mean that all explanations are valid, but that causation occurs at many levels and that specific events are caused by a complex set of factors. Instead of aiming to find the evidence to solve the problem, RED aims to gain a higher explanatory validity which recognises that the significance of different contributions to an overall account forces us to reflect upon the limitations of each individual explanatory approach, as the differences encourage reflexivity if they are actively engaged with. In this way, RED offers a means of balancing the need to question all taken-for-granted assumptions with the need to respect a range of explanations. This is in contrast to non-reflexive epistemological diversity, which is often seen in interdisciplinary work and is based upon stacking up the results of insular research traditions confined within specific and self-referential disciplinary fields. Adopting RED in the field of EBD would allow alternative frameworks to fruitfully co-exist alongside the existing approaches, enabling the inclusion of research insights that address the ineffable and thus achieve a higher explanatory validity, without which the situation will remain unclear and it will be difficult to intervene in the practical field with the necessary attuning strategies. 


\section{Conclusion}

There is not one noise problem in hospitals that can be solved, but there are different noise problems that can be managed adequately if approached differently. Two interpretations of Nightingale's famous quote served as a framework for mapping the two existing approaches to tackling the noise problem in hospitals today. The first interpretation takes the quote to be a simple expression of the need to lower measurable noise levels in hospitals (the noise reduction approach), whereas the second interpretation includes considerations on the subjective experience (the human-centred approach). Although the two main approaches are important steps towards the creation of a better acoustic environment in hospitals, a third interpretation should be included that highlights the impact of the multisensory and contextual conditions on the experience of noise. Therefore, the proposed attuning approach addresses how the ambiguous auditory experience in hospitals, as a dynamic interplay between the atmospheric hospital environment and the active coping and habituation strategies, develops and forms our relationship to the overall hospital environment. In order to adequately address the noise problem in hospitals in the future, all three approaches must be able to co-exist, develop and ideally work together.

This argument finds support in Pascal Amphoux's three different operative attitudes, which he proposes should all be equally engaged with when managing complex acoustic environments in urban space (Hellström, 2003, p. 169). The noise reduction approach fits the first attitude, termed 'Diagnosis of the Environment', which focusses on protection from noise pollution. The human-centred approach fits the second attitude, termed 'Managing the Milieu', which focusses on offensive strategies to manage conflicts, regulate social interaction and equip people with the instruments needed to control a private sonic milieu. And the attuning approach fits the third operative attitude, termed 'Creation of the Landscape', which focusses on creative operations to stimulate consciousness of the acoustic space through sonic design. In this view, the absence of a plan for the third operative attitude in hospitals today calls for a sonic designer that can address both technical aspects towards dealing with architectural, social, cultural and perceptual criteria as well as handling experiential qualities with regard to the actual listening situation. With a focus on the relation between listener and environment and on how listening perception operates when acting in a built environment, such work should concentrate on how the environment activates us and on how we activate the environment through listening (Hellström, 2003, p. 37).

The challenge for future work is therefore to develop strategies that provide a broad diversity of opportunities for individuals to exercise personal control as a way of coping, including a variety of quiet and lively atmospheres over a more 
uniform set of acoustic environments that comply with noise limits (Andringa \& Lanser, 2013, p. 1457). Attuning strategies should move beyond reception-based sound design towards doing with sound, through enactive sonic design that offers possibilities through affordances in the environment to satisfy the shifting needs. This could be developed through the use of interactive sound technologies that have the potential to increase the malleability of sound and consequently enhance the active engagement of users with sound and listening, which is often perceived as ephemeral and uncontrollable (Franinović \& Salter, 2013, p. 43). While this study does not offer a conclusive answer to the question of how to unfold attuning strategies in practice, it appeals to EBD to stretch its methodological and disciplinary boundaries to acknowledge 'what we're doing when we're listening, whenever and wherever that listening happens' (Kassabian, 2013, p. 117) as a first step towards bridging the current gap in the field. ${ }^{6}$

The attuning approach connects to recent developments in the field of music therapy under the name of Health Musicing (Bonde, 2011, p. 121), which is defined as the common core of any use of music experiences to regulate emotional or relational states or to promote well-being, be it therapeutic or not, professionally assisted or self-made. In this way, Health Musicing can be observed in any social or individual practice where people use music experiences to create meaning and coherence in states and times of adversity. In this context the attuning approach could be seen as a fruitful expansion from music experiences to include sound design, sound art and enactive sound design through technology.

\section{References}

Andringa, T.C., \& Lanser, J.J.L. (2013). How pleasant sounds promote and annoying sounds impede health: A cognitive approach. International Journal of Environmental Research and Public Health, 10(4), 1439-1461. Retrieved from: http://www.mdpi.com/1660-4601/10/4/1439/pdf

Andringa, T.C., Weber, M., Payne, S.R., Krijnders, J.D., Dixon, M.N., Linden, R.V.D., DeKock, E.G.L., \& Lanser, J.L. (2013). Positioning soundscape research and management. The Journal of the Acoustical Society of America, 134(4), 2739-2747.

Annerstedt, M. (2012). Nature and public health-aspects of promotion, prevention, and intervention. Socialmedicinsk tidskrift, 89(1), 82.

Ash, J., \& Gallacher, L.A. (2015). Methodologies of Embodiment: Inscribing Bodies in Qualitative Research. In M. Perry \& C.L. Medina (Eds.), Methodologies of Embodiment: Inscribing Bodies in Qualitative Research. New York: Taylor \& Francis.

Becker, F., Bonaiuto, M., Bilotta, E., \& Bonnes, M. (2011). Integrated Healthscape Strategies: An Ecological Approach to Evidence-Based Design. HERD: Health Environments Research \& Design Journal, $4(4), 114-129$.

Biddle, I. (2009). Visitors, or The Political Ontology of Noise. Radical Musicology, 4. Retrieved from: http://www.radical-musicology.org.uk/2009.htm

Bonde, L.O. (2011). Health Musicing - Music Therapy or Music and Health? A model, empirical examples and personal reflections. Music and Arts in Action, 3(2), 120-140. 
Busch-Vishniac, I.J., West, J.E., Barnhill, C., Hunter, T., Orellana, D., \& Chivukula, R. (2005). Noise levels in Johns Hopkins Hospital. The Journal of the Acoustical Society of America, 118(6), 3629.

Call, R.B. (2007). Sound practices: noise control in the healthcare environment. Academy Journal. Retrieved from: http://www.hermanmiller.com/research/research-summaries/sound-practices-noise-control-in-the-healthcare-environment.html

Clarke, E. (2005). Ways of Listening: An Ecological Approach to the Perception of Musical Meaning. Oxford, UK: Oxford University Press.

Cordova, A.C., Logishetty, K., Fauerbach, J., Price, L.A., Gibson, B.R., \& Milner, S.M. (2013). Noise levels in a burn intensive care unit. Burns, 39(1), 44-48.

David, M. (2005). Science in Society. London: Palgrave Macmillan.

DeNora, T. (1999). Music as a technology of the self. Poetics, 27(1), 31-56.

Dirckinck-Holmfeld, K., Heslet, L., \& Rigshospitalet. (2007). Sansernes hospital. Copenhagen, Denmark: Arkitektens Forlag.

Edensor, T. (2012). Geographies of Rhythm: Nature, Place, Mobilities and Bodies. Ashgate.

Flatley, J. (2009). Affective mapping: Melancholia and the politics of modernism. Harvard University Press.

Frandsen, A.K., Ryhl, C., Folmer, M.B., Fich, L.B., Øien, T.B., Lykke Sørensen, N., \& Mullins, M. (2009). Helende arkitektur. Institut for Arkitektur og Design skriftserie Vol. 29.

Franinović, K., \& Salter, C. (2013). The Experience of Sonic Interaction. In Franinović, K., \& Serafin, S. (Eds.), Sonic Interaction Design (pp. 39-75). Cambridge, Massachusetts: The MIT Press.

Grumet, G.W. (1993). Pandemonium in the Modern Hospital. New England Journal of Medicine, 329(3), 211-212.

Harman, G. (2013). Undermining, Overmining, and Duomining: A Critique. In Sutela, J. (Ed.), ADD Metaphysics - Let the material not confine. Helsinki, Finland: Aalto University Digital Design Laboratory.

Hellström, B. (2003). Noise Design - Architectural Modelling and the Aesthetics of Urban Acoustic Space. Göteborg, Sweden: Bo Ejeby Förlag.

Højlund, M., \& Kinch, S. (2014). Alarming atmospheres: Embodied sound habituation as design strategy in a neuro-intensive care unit. Journal of Sonic Studies, 6(1). Retrieved from: http://journal. sonicstudies.org/vol06/nr01/a02

Ihde, D. (2007). Listening and voice: phenomenologies of sound (2nd ed.). Albany, NY: State University of New York Press.

Ingold, T. (2011). The Perception of the Environment: Essays on Livelihood, Dwelling and Skill. London: Routledge.

Ising, H., \& Kruppa, B. (2004). Health Effects Caused by Noise: Evidence in the Literature from the Past 25 Years. Noise and Health, 6(22), 5-13.

Johansson, L., Bergbom, I., \& Lindahl, B. (2012). Meanings of being critically ill in a sound-intensive ICU patient room-A phenomenological hermeneutical study. The open nursing journal, 6(108). Retrieved from: http://www.ncbi.nlm.nih.gov/pmc/articles/PMC3439833/pdf/TONURSJ-6-108. pdf

Joseph, A., \& Ulrich, R. (2007). Sound control for improved outcomes in healthcare settings. Concord, CA: Center for Health Design.

Kang, J., Chourmouziadou, K., Sakantamis, K., Wang, B., \& Hao, Y. (Eds.) (2013). Soundscape of European Cities and Landscapes. Retrieved from: http://soundscape-cost.org/documents/COST_TD0804_Ebook_2013.pdf

Kassabian, A. (2013). Ubiquitous listening: affect, attention, and distributed subjectivity. Berkeley: University of California Press.

Lind, T.T. (2007). Meaning, Power and Exoticism in Medicinal Music: A Case Study of MusiCure in Denmark. Ethnomusicology Forum, 16(2), 209-242.

Mackrill, J., Cain, R., \& Jennings, P. (2013). Experiencing the hospital ward soundscape: Towards a model. Journal of Environmental Psychology, 36, 1-8. 
Nightingale, F. (1946). Notes on nursing: What it is, and what it is not. Philadelphia: J.B. Lippincott Company.

Okcu, S., Ryherd, E.E., Zimring, C., \& Samuels, O. (2011). Soundscape evaluations in two critical healthcare settings with different designs. The Journal of the Acoustical Society of America, 130(3), 1348-1358. Retrieved from: http://dx.doi.org/10.1121/1.3607418

Radley, A., \& Taylor, D. (2003). Images of recovery: A photo-elicitation study on the hospital ward. Qualitative Health Research, 13(1), 77-99.

Rice, T. (2003). Soundselves: An acoustemology of sound and self in the Edinburgh Royal Infirmary. Anthropology Today, 19(4), 4.

Rice, T. (2013). Hearing and the Hospital: Sound, Listening, Knowledge and Experience. Herefordshire, UK: Sean Kingston Publishing.

Ryherd, E.E., West, J.E., Busch-Vishniac, I.J., \& Waye, K.P. (2008). Evaluating the Hospital Soundscape. Acoustics Today, 4(4), 22-29.

Schwartz, H. (2013). Inner and Outer Sancta: Earplugs and Hospitals. In Pinch, T.J., \& Bijsterveld, K. (Eds.), The Oxford Handbook of Sound Studies (p. 593). New York: Oxford University Press.

Shattell, M., Hogan, B., \& Thomas, S.P. (2005). "It's the People that Make the Environment Good or Bad": The Patient's Experience of the Acute Care Hospital Environment. AACN Advanced Critical Care, 16(2), 159-169.

Stankos, M., \& Schwarz, B. (2007). Evidence-based design in healthcare: A theoretical dilemma. Interdisciplinary Design and Research e-Journal, 1(1).

Thibaud, J.-P. (2011). The Sensory Fabric of Urban Ambiances. The Senses \& Society, 6(2), 203-215. doi:1 $0.2752 / 174589311 X 12961584845846$

Thibaud, J.-P. (2014). The backstage of urban ambiances: When atmospheres pervade everyday experience. Emotion, Space and Society.

Thibaud, J.-P., \& Amphoux, P. (2013). Silencing the city? SoundEffects - An Interdisciplinary Journal of Sound and Sound Experience, 3(3), 61-70. Retrieved from: http://www.soundeffects.dk/article/ view/18441

Thomson, I.D. (2011). Heidegger, Art, and Postmodernity. Cambridge, UK: Cambridge University Press.

Topf, M.M. (2000). Hospital noise pollution: an environmental stress model to guide research and clinical interventions. Journal of Advanced Nursing, 31(3), 520.

Vannini, P. (2015). Non-Representational Methodologies: Re-Envisioning Research: Taylor \& Francis.

Wiese, C.H. (2010). Investigation of Patient Perception of Hospital Noise and Sound Level Measurements: Before, During, and After Renovations of a Hospital Wing. University of Nebraska, Nebraska, USA. Retrieved from http://digitalcommons.unl.edu/archengdiss/4

Wolf, J.A., \& Madaras, G.S. (2012). Charting a Course to Quiet: Addressing the Challenge of Noise in Hospitals. Texas: The Beryl Institute.

\section{Notes}

1 The names of approaches and strategies are termed by the author.

2 See: http://www.godtsygehusbyggeri.dk/Maal\%20og\%20styring/ /media/Files/Maal\%20og\%20styring/Vision/Sygehusbyggeri\%20med\%20patienten\%20i\%20centrum.ashx

3 Another use of the quote as an argument for noise reduction can be found in a TED talk by Julian Treasure from 2014: http://tedmed.com/talks/show?id=293030

4 Acousmatic sounds refer to sounds that have no immediate identifiable causes.

5 See: https://www.nordsjaellandshospital.dk/afdelinger-og-klinikker/graviditet-og-foedsel/foedslen/ Sider/Sansefoedestuer.aspx \& http://www.wavecare.com/sensory-delivery-rooms2.html

6 I have developed a case study together with architect Sofie Kinch to experiment with how to apply and implement the attuning approach in practice. We developed the interactive furniture KidKit for the 
Neuro-Intensive Care Unit at Aarhus University Hospital to prepare children for the alarming atmosphere they will enter when visiting a hospitalised relative. KidKit invites children to become accustomed to the alarming sounds sampled from the ward while they are waiting in the waiting room. By actively triggering the sounds built into KidKit the child can habituate them through a process of synchronising them with their own bodily rhythms. Hereby the child can establish, in advance, a familiar relationship with the alarming sounds in the ward, enabling them to focus more on the visit with the relative (Højlund \& Kinch, 2014). 